\title{
Botanical Pesticides and Luring Efficacy of Natural Substances in the Management of Sorghum Chafer under Field and Laboratory Conditions
}

\author{
Asmare Dejen \\ Wollo University, Dessie, Ethiopia \\ Email: Asmare di@fastmail.fm
}

Received 2 July 2014; revised 11 August 2014; accepted 21 September 2014

Copyright (C) 2014 by author and OALib.

This work is licensed under the Creative Commons Attribution International License (CC BY). http://creativecommons.org/licenses/by/4.0/

(c) $\underset{\mathrm{EY}}{\mathrm{B}}$ Open Access

\begin{abstract}
Sorghum chafer, Pachnoda interrupta (Olivier) (Coleoptera: Scarabaeidae: Cetoniinae) is one of the major problems on sorghum. The purpose of this study was to investigate alternative management methods. The studies were conducted under laboratory and field conditions. We tested efficacy of Jatropha curcas, Lantana camara, Croton mychrostaches, Agave sp. (sisal) and Melia azadrech. The lure effects of banana, guava, local beer residue (Atela), malt and molasses were evaluated. The result from laboratory showed that C. mychrostaches, L. camara, M. azadrech, Agave sp. and $J$. curcas caused beetle mortality of $44 \%-60 \%, 24 \%-64 \%, 43 \%-63 \%, 45 \%-64 \%$, and $65 \%$ $\mathbf{7 8 \%}$, respectively. Also with the result from field it was confirmed that $C$. mychrostaches, $L$. camara, $M$. azadrech, Agave sp. and J. curcas caused beetle mortality of $23 \%-56 \%, 27 \%-55 \%, 36 \%-58 \%, 40 \%$ - 55\% and $76 \%-82 \%$, respectively. In the bait experiment, a higher number of beetles were attracted using banana ( $>3000$ beetles) and guava fruit ( $>3500$ beetles) than the other attractants. Male beetles were more attracted than the female beetles. Thus, we recommended that all botanical pesticides with banana and guava fruits as baits could be used in sorghum chafer management.
\end{abstract}

\section{Keywords}

Pachnoda interrupta, Ethiopia, Banana, Chafer

Subject Areas: Agricultural Science, Entomology, Plant Science

\section{Introduction}

Pachnoda interrupta (Olivier) (Coleoptera: Scarabaeidae: Cetoniinae) is a polyphagous pest distributed particu-

How to cite this paper: Dejen, A. (2014) Botanical Pesticides and Luring Efficacy of Natural Substances in the Management of Sorghum Chafer under Field and Laboratory Conditions. Open Access Library Journal, 1: e821.

http://dx.doi.org/10.4236/oalib.1100821 
larly in Africa [1]. In Ethiopia, surveys conducted about 20 years ago revealed the presence of nine species of Pachnoda, one represented by two subspecies [2]. Except, the two species, P. stehelini Sch. and P. abyssinica Blan. were recorded in greater than 2000 m.a.s.l. Other species were found in the acacia woodlands distributed between 800 and 1800 m.a.s.l. [3]. Among the nine species, the sorghum chafer, Pachnoda interrupta, has become a well-established regular pest in the last eight years. It attacks a wide range of crops (over 35 types), of which sorghum is the major one [4] [5].

[6] [7] had reported that sorghum chafer was as a major insect pest of sorghum since 1977 in Ethiopia. The beetles feed on flowers, milky grains or early dough grains of sorghum and millet causing sterilization of florets or damage to kernels. The genus Pachnoda is originated in Africa and Arabia where it occurs as a large number of species; the adult beetles are recorded damaging flowers and fruits of quite a large cultivated plants, including peach, cotton, citrus, rose, mango, acacia, maize, sunflower, and the milky grain of sorghum and pear millet [8]. In Mali under cage experiment sorghum chafer could cause sorghum yield losses from $10 \%$ to $49 \%$ with beetle densities of 1 - 10 beetles per head. [1] [3] reported that sorghum chafer together with grasshopper destroyed $50 \%$ of potential millet harvest in Mali. In Ethiopia sorghum chafer caused more than $80 \%$ yield loss on sorghum and $20 \%$ on maize. [4] [9] suggested that, for the effective management of sorghum chafer one should first identify the larval breeding areas, monitoring larval densities and apply appropriate control measures before pupation. Management of sorghum chafer through synthetic chemicals in the form of spraying is impossible because of long height of sorghum (2 - $3 \mathrm{~m}$ ) and it causes health and environment hazard. Behavioural and antennal responses of the sorghum chafer Pachnoda interrupta (Olivier) were tested to the synthetic compounds, such as eugenol, methyl salicylate, methyl anthranilate, isoamyl acetate and butyl butyrate. In the field, all odourbaited traps, except isoamyl acetate applied on cotton dispensers, were significantly more attractive than blank (unbaited) traps and all compounds, except isoamyl acetate elicited dose-dependent responses in both male and female antennae [5].

Therefore, the objectives of the studies were to evaluate alternate bio-pesticides, to select best attractant and to investigate the response of adult male and female beetles towards different odours of attractants.

\section{Materials and Methods}

\subsection{Study Site Description}

Bati distinct, is situated in $39^{\circ} 59^{\prime} \mathrm{E}$ and $11^{\circ} 11^{\prime} \mathrm{N}$ and with an altitude between 1300 - 1657 meter above sea level. It received rainfall twice a year. The short rain period (April and May) and the main rainfall season (June to September). The study was carried out during the main rainfall season. Bati district receives a mean annual rainfall of $1183 \mathrm{~mm}$ and there was enough rain during the main season. The mean minimum and maximum temperature are $13.6^{\circ} \mathrm{C}$ and $28.3^{\circ} \mathrm{C}$, respectively. During the experimental season, the mean relative humidity of Bati is $67.2 \%$. The major soil types of the district are alluvial, clay and loam. Bati is one of the areas districts that where sorghum chafer caused sorghum grain yield losses.

\subsection{Botanical Pesticides}

The tested botanical pesticides are available in all locations. The studies were carried out under laboratory and field conditions in 2006 and 2007. The field experiments were conducted in Oromia administration zones (Bati district) of Amhara Regional State, Ethiopia. Laboratory experiment was carried out at Sirinka Agricultural Research Centre.

Randomised complete design (RCD) and randomised complete block design (RCBD) with three replications were used for under laboratory and field conditions, respectively and three times replicated. The treatments were Jatropha curcas (physics nut), Lantana camara, Croton mychrostaches (Bisana), Schinus molle and sisal. Fresh leaves of each botanical were collected and chopped with mortal. The $1-2 \mathrm{~kg}$ of chopped leaves of each botanical pesticides were squeezed manually to obtain enough juice (2 lt). Little water $(0.25 \mathrm{lt})$ was used to enhance enough juice. The extracted juice (2 lt) of each botanical (1.5 lt) was allowed to stand for seven days before application under room temperature. The food bait (three banana fruits (200 - $300 \mathrm{~g})$ was mixed uniformly with each fermented botanical juice $(1.5 \mathrm{ml})$ and kept in plat plastic jar until used. During laboratory experimentation, hundred adult beetles were added to plastic jar $(35 \mathrm{~cm} \times 25 \mathrm{~cm} \times 30 \mathrm{~cm}$ ) three banana and extracts of each botanical pesticide. The numbers of dead and live beetles were recorded after an hour of beetles exposing on each treatment. 
Similar preparation and procedures were followed as that of laboratory experiments for field experiment. The mixed treatments (banana and botanical juices) were put in flat clay pots $(25 \mathrm{~cm} \times 20 \mathrm{~cm} \times 10 \mathrm{~cm})$. The mixtures were suspended or hanged on acacia species, Zizyphus spinacristy and Carissa edulis flowers that adult beetles fed on [9]. Each treatment was kept away one kilometer apart from each other to avoid confusion of the beetles towards the odour of each bait. The number of dead beetles fallen under trees was counted.

\subsection{Food Baits/Luring Substances}

Luring efficacy of molasses (sugar factory by-product), malt (beer factory), fruits (banana, guava, mango) and local beer residue (Atela) were evaluated for their adult beetles attraction. The treatments were a mixture of each fruit species and attractants. Randomised complete block design with three replications was used. A single fruit (200 - $300 \mathrm{~g}$ ) of each type and small amount molasses ( $0.5 \mathrm{lt})$, malt (400 g) and local beer (1 lt) residue (300 g) were mixed. The mixtures were put in flat bottom containers (3 lt) and hanged on trees or bushes. Similarly, each attractant was mixed with a teaspoon of carbaryl 85 WP for comparison purpose. The dead and weaken beetles fallen down on the ground after feeding were counted. Percent mortality was calculated based on dead and total attracted beetles after an hour exposure.

The number of attracted male and females beetle to each attractant were counted and percent male and female was calculated based on the total attracted beetles.

\section{Result and Discussion}

\subsection{Botanical Pesticides}

Beetle mortalities of $45 \%-64 \%, 24 \%-64 \%, 44 \%-60 \%, 43 \%-63 \%$ and $65 \%-78 \%$ were recorded obtained using Sisal, L. camara, C. mychrostaches, P. lilac and J. curcas, respectively at laboratory condition (Figure 1) in both years. All botanicals also showed good potential in beetle mortality under field condition; J. carcus caused higher mortality $(75.9 \%-81.6 \%)$ than the other botanicals tested in both years. Beetle mortalities of $39.6 \%$ - 55.4\%, 75.9\% - 81.6\%, 26.5\% - 55.3\%, 22.7\% - 55.6\% and 35.8\% - 57.9\% were recorded using sisal, $J$. curcas, L. camara, C. mychrostaches and S. mollie, respectively at field condition (Table 1). Similarly beetles mortality trends were recorded at laboratory condition. Thus, beetle mortalities of $45 \%$ - 64\%, $24 \%$ - 64\%, $44 \%$ $60 \%, 43 \%-63 \%$ and $65 \%-78 \%$ were recorded obtained using sisal, L. camara, C. mychrostaches, P. lilac and J. curcas, respectively at laboratory condition (Figure 1) in both years. [10] [11] reported that water extract of Birbira seed (filtered with cheese cloth) caused 45\% - 60\% mortality sorghum chaffer within 24 - 48 hrs and this was significantly higher than mortality caused by the standard insecticide, carbaryl.

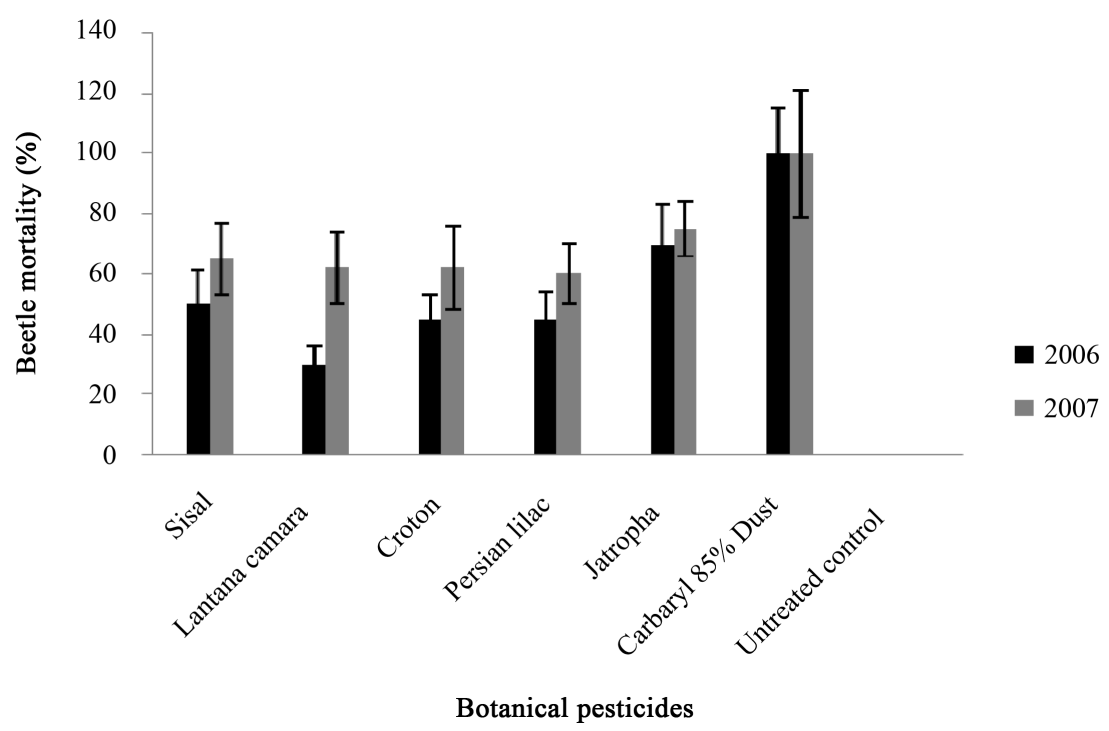

Figure 1. The efficacy of botanical pesticides on sorghum chafer mortality under laboratory conditions. 
Bio-pesticides tested at field condition were as effective as laboratory condition in beetle mortality (Table 1 and Figure 1). During the data collection, it was observed that all beetles fed on the mixture of botanical pesticides were weakened (49\% - 42\%) and fell down. Moreover, it was observed that the weakened and fallen beetles to ground were easily exposed to natural enemies like birds and ants. Besides exposed to natural enemies, it was easy to spray chemicals and to kill mechanically. These types of point applications were accepted by farmers because the spray of chemicals in the fields and grazing lands was harmful to their animals and bees as well as polluted the drinking water.

\subsection{Luring the Adult Beetles}

Significantly a higher number of beetles were attracted to banana ( $>3000$ beetles) and guava fruit ( $>3500$ beetles) while the other baits were less efficient (Figure 2). The local beer residue (atela) and the factory by products (malt and molases) were not effective attractants as compared to the fruits. Adult male beetles were more attracted by baits than females' beetles in both years (Table 2). [10] reported that volatile compounds originating from sorghum and other host plants are highly attractive to the beetles. When these compounds alone or in mixtures are deployed as lures in traps, a high number of beetles are caught. Field experiments also indicate that

Table 1. The effect of botanical pesticides on sorghum beetles mortality (\%) under field condition.

\begin{tabular}{ccc}
\hline & \multicolumn{2}{c}{ Adult beetle mortality (\%) } \\
\cline { 2 - 3 } Botanical pesticides & 2006 & 2007 \\
\cline { 2 - 3 } Sisal & $55.4 \pm 6.1 \mathrm{~b}$ & $39.6 \pm 8.1 \mathrm{c}$ \\
Jatropha curcas & $81.6 \pm 10.1 \mathrm{a}$ & $75.9 \pm 11.1 \mathrm{ab}$ \\
Lantana camara & $55.3 \pm 5.3 \mathrm{~b}$ & $26.5 \pm 2.5 \mathrm{~d}$ \\
Croton mychrostaches & $55.6 \pm 4.6 \mathrm{~b}$ & $22.7 \pm 2.1 \mathrm{~d}$ \\
Shines mollie & $57.9 \pm 7.0 \mathrm{~b}$ & $35.8 \pm 7.6 \mathrm{c}$ \\
Carbaryl 85\% & $100.0 \pm 9.6 \mathrm{a}$ & $100.0 \pm 11.1 \mathrm{a}$ \\
Control & 0 & 0 \\
CV $(\%)$ & 22.9 & 36.1 \\
\hline
\end{tabular}

Mean $( \pm \mathrm{SE})$ within columns, along each district, followed by the same letters do not differ significantly at the $5 \%$ (multiple range test).

Table 2. Attracted male to female ratio using different baits at Bati district in 2006 and 2007.

\begin{tabular}{|c|c|c|c|c|c|}
\hline \multirow{2}{*}{ Year } & \multirow{2}{*}{ Attractants } & \multicolumn{2}{|c|}{ Mean number of attracted beetles } & \multicolumn{2}{|c|}{ Attracted (\%) } \\
\hline & & Males & Females & Males & Females \\
\hline \multirow{4}{*}{2006} & Banana & $1977 \pm 21.4 b$ & $1063 \pm 11.1 \mathrm{a}$ & $65 \pm 6.3 a$ & $35 \pm 5.0 a$ \\
\hline & Guava & $2278 \pm 22.2 \mathrm{a}$ & $1257 \pm 8.9 a$ & $64 \pm 4.1 \mathrm{a}$ & $36 \pm 3.1 \mathrm{a}$ \\
\hline & Atela & $23 \pm 2.1 c$ & $21 \pm 4.1 b$ & $52 \pm 2.3 b$ & $48 \pm 7.3 a$ \\
\hline & CV (\%) & 23 & 28 & 11 & 13 \\
\hline \multirow{4}{*}{2007} & Banana & $1605 \pm 12.1 \mathrm{a}$ & $869 \pm 20.2 a$ & $65 \pm 5.7 a$ & $35 \pm 2.3 a$ \\
\hline & Atela & $118 \pm 11.4 \mathrm{c}$ & $108 \pm 8.2 b$ & $52 \pm 2.9 b$ & $48 \pm 5.1 a$ \\
\hline & Guava & $250 \pm 9.0 b$ & $146 \pm 13.1 b$ & $63 \pm 6.6 a$ & $37 \pm 6.0 \mathrm{a}$ \\
\hline & CV (\%) & 21.4 & 31.4 & 12.5 & 10.2 \\
\hline
\end{tabular}

Mean $( \pm$ SE) within columns, along each district, followed by the same letters do not differ significantly at the $5 \%$ (multiple range test). 


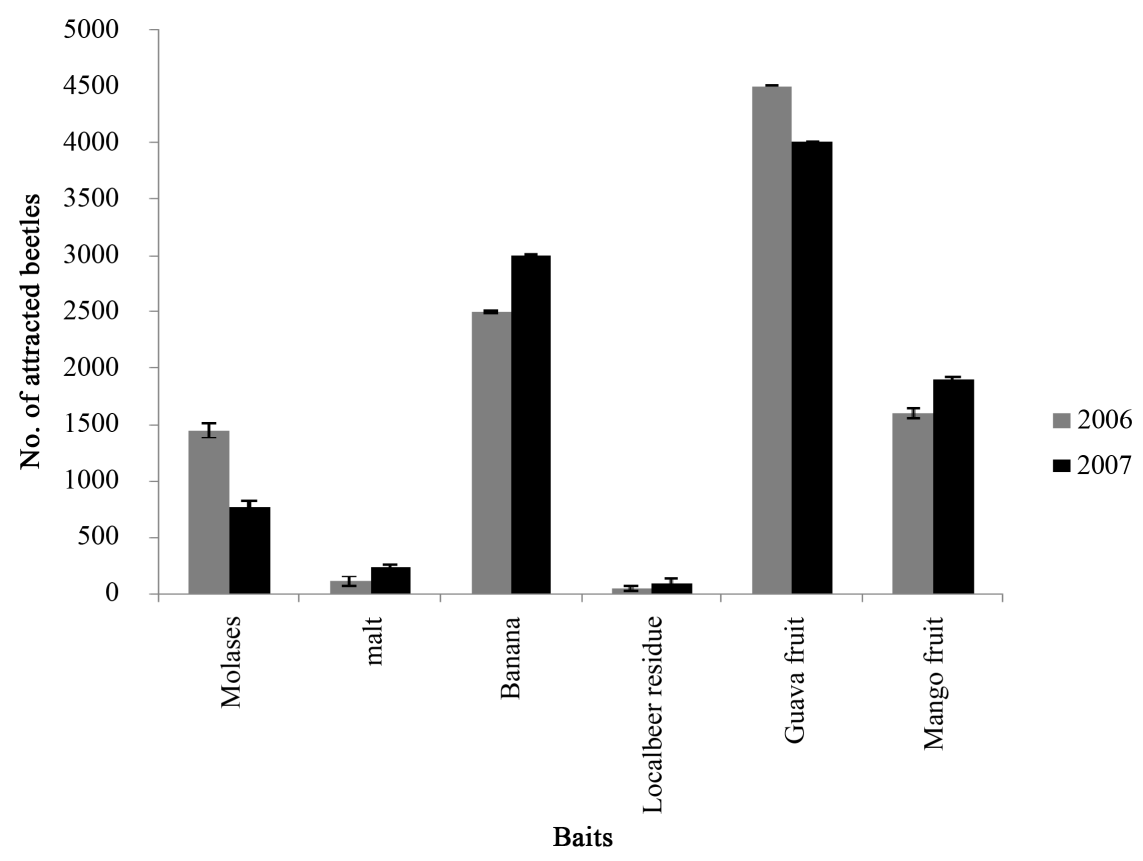

Figure 2. The effect of different baits in luring sorghum chafer beetle at Bati district.

a combination of pheromones and plant compounds constitutes an even more powerful attractant to the sorghum chafer.

\section{References}

[1] Grunshaw, J.P. (1992) Field Studies on the Biology and Ecology Importance of Pachnoda interrupta (Coleoptera: Scarabaeidae) in Mali, West Africa. Bulletin of Entomological Research, 82, 19-27. http://dx.doi.org/10.1017/S0007485300051452

[2] Clark, R.O.S. and Crowe, T.J. (1977) The Genus Pachnoda in Ethiopia. Identification, Pest Status and Control of the Species. IAR, Addis Ababa.

[3] Loch, C., Mohmoud, M. and Sidibe, A. (1998) Agricultural Economics Report 1987. Mali Millet Pest Control Project R1521 (R). Natural Resources Institutes, Chatham, 69.

[4] Yitbarek, W.H., Emiru, S., Bekele, J., Merid, N., Hansson, B.S. and Ylva, H. (2007) Behavioural and Electrophysiological Response of Sorghum Chafer Pachnoda interrupta (Coleoptera: Scarabaeidae) to Plant Compounds. International Journal of Tropical Insect Science, 27, 53-61. http://dx.doi.org/10.1017/S1742758407780852

[5] Yitbarek, W.H. and Hiwot, L. (1999) Preliminary Yield Loss Assessment on Sorghum and Maize Due to Sorghum Chafer. Kombolcha, Ethiopia (Unpublished).

[6] Crowe, T.J., Taddess, G.M. and Tsedeke, A. (1977) An Annotated Lists of Insect Pests of Field Crops in Ethiopia. IAR, Addis Ababa, 71.

[7] Crowe, T.J. and Shitaye, G.M. (1977) Crop Pest Handbook. 3rd Revised Edition, Ethiopia Agricultural Institute, Addis Ababa.

[8] Hill, D. (1994) Agricultural Entomology. Timber Press, Portland, 259-260.

[9] Asmare, D. and Yeshitila, M. (2014) Ecology and Field Biology of the Sorghum Chafer. Pachnoda interrupta (Olivier) (Coleoptera: Scarabaeidae) in Ethiopia. Advanced in Entomology, 2, 8-13. http://dx.doi.org/10.4236/ae.2014.21002

[10] Bekele, J., Daniel, G., Merid, N. and Emiru, S. (2005) Toxicity of Birbira (Milletia ferruginea) Seed Crude Extracts to Some Insect Pests as Compared to Other Botanical and Synthetic Insecticides. 11th NAPRECA Symposium Book of Proceedings, Antananarivo, 88-96.

[11] Jonas, B., Yitbarek, W., Merid, N., Emiru, Bekele, J., Bill, H. and Ylva, H. (2008) Plant and Pheromone Odor Lures for Environmentally Sustainable Control of the Sorghum Chafer, Pachnoda interrupta. Meeting Global Challenges in Research Cooperation. Proceedings of a Conference and Workshop in UPPSALa, Uppsala, 27-29 May 2008, 659. 